\title{
Methotrexate Prodrugs Sensitive to Reactive Oxygen Species for the Improved Treatment of Rheumatoid Arthritis
}

Andersen, Nikolaj S.; Peiro Cadahia, Jorge; Previtali, Viola; Bondebjerg, Jon; Hansen, Christian A.; Hansen, Anders E.; Andresen, Thomas Lars; Clausen, Mads H.

\author{
Published in: \\ European Journal of Medicinal Chemistry
}

Link to article, DOI:

10.1016/j.ejmech.2018.07.045

Publication date:

2018

Document Version

Peer reviewed version

Link back to DTU Orbit

Citation (APA):

Andersen, N. S., Peiro Cadahia, J., Previtali, V., Bondebjerg, J., Hansen, C. A., Hansen, A. E., Andresen, T. L., \& Clausen, M. H. (2018). Methotrexate Prodrugs Sensitive to Reactive Oxygen Species for the Improved Treatment of Rheumatoid Arthritis. European Journal of Medicinal Chemistry, 156, 738-746. https://doi.org/10.1016/j.ejmech.2018.07.045

\section{General rights}

Copyright and moral rights for the publications made accessible in the public portal are retained by the authors and/or other copyright owners and it is a condition of accessing publications that users recognise and abide by the legal requirements associated with these rights.

- Users may download and print one copy of any publication from the public portal for the purpose of private study or research.

- You may not further distribute the material or use it for any profit-making activity or commercial gain

- You may freely distribute the URL identifying the publication in the public portal 


\section{Methotrexate Prodrugs Sensitive to Reactive Oxygen Species}

\section{for the Improved Treatment of Rheumatoid Arthritis}

Nikolaj S. Andersen ${ }^{\dagger}$, Jorge Peiró Cadahía ${ }^{\dagger}$, Viola Previtali ${ }^{\dagger}$, Jon Bondebjerg ${ }^{\S}$, Christian A. Hansen, Anders E. Hansen ${ }^{ \pm}$, Thomas L. Andresen ${ }^{\ddagger}$, and Mads H. Clausen ${ }^{\dagger, *}$

†Center for Nanomedicine \& Theranostics, Department of Chemistry, Technical University of Denmark, Kemitorvet 207, DK-2800, Kongens Lyngby, Denmark

§MC2 Therapeutics, Agern Alle 24-26, 2970 Hørsholm, Denmark

\#Capdelta Group Aps, C/O Kavsbjerglund 30, DK-2740 Skovlunde, Denmark

\pm Department of Clinical Physiology, Nuclear Medicine \& PET and Cluster for Molecular Imaging, Rigshospitalet and University of Copenhagen, DK-2100 Copenhagen, Denmark

‡Center for Nanomedicine \& Theranostics, Department of Micro- and Nanotechnology, Technical University of Denmark, Ørsteds Plads, Building 345, DK-2800 Kongens Lyngby, Denmark

*Corresponding author, Department of Chemistry, Center for Nanomedicine \& Theranostics, Technical University of Denmark, Kemitorvet 207, DK-2800 Kongens Lyngby, Denmark. Tel.: +45 45252131. E-mail: mhc@kemi.dtu.dk 


\section{Abstract}

Methotrexate (MTX) is the standard of care in the treatment of rheumatoid arthritis (RA), a common autoimmune disease that is characterized by chronic inflammation in the synovial membrane of joints. Unfortunately, MTX suffers from high discontinuation rates due to a large variability in efficacy and, in particular, adverse effects. As inflammation is associated with elevated levels of reactive oxygen species (ROS) like $\mathrm{H}_{2} \mathrm{O}_{2}$, we propose to improve treatment through site-selective delivery of MTX to inflammatory tissue by use of a $\mathrm{H}_{2} \mathrm{O}_{2}$ sensitive MTX prodrug. To establish proof proof-of-concept, two novel $\mathrm{H}_{2} \mathrm{O}_{2}$ sensitive, thiazolidinone-based MTX prodrugs were synthesized and evaluated for this purpose. MTX- $\gamma$-thiazolidinone (MTX- $\gamma-\mathrm{TZ}$ ) exhibited the most promising properties - good to high chemical and metabolic stability, excellent aqueous solubility, while being activated when subjected to patho-physiological concentrations of $\mathrm{H}_{2} \mathrm{O}_{2}$. In vivo, MTX- $\gamma$-TZ exhibited comparable efficacy to MTX in a murine collagen type II-induced arthritis (CIA) model while treated mice showed indications of reduced toxicity as their body weight decreased less towards the end of the study, compared to the MTX-treated group.

\section{Graphical abstract}

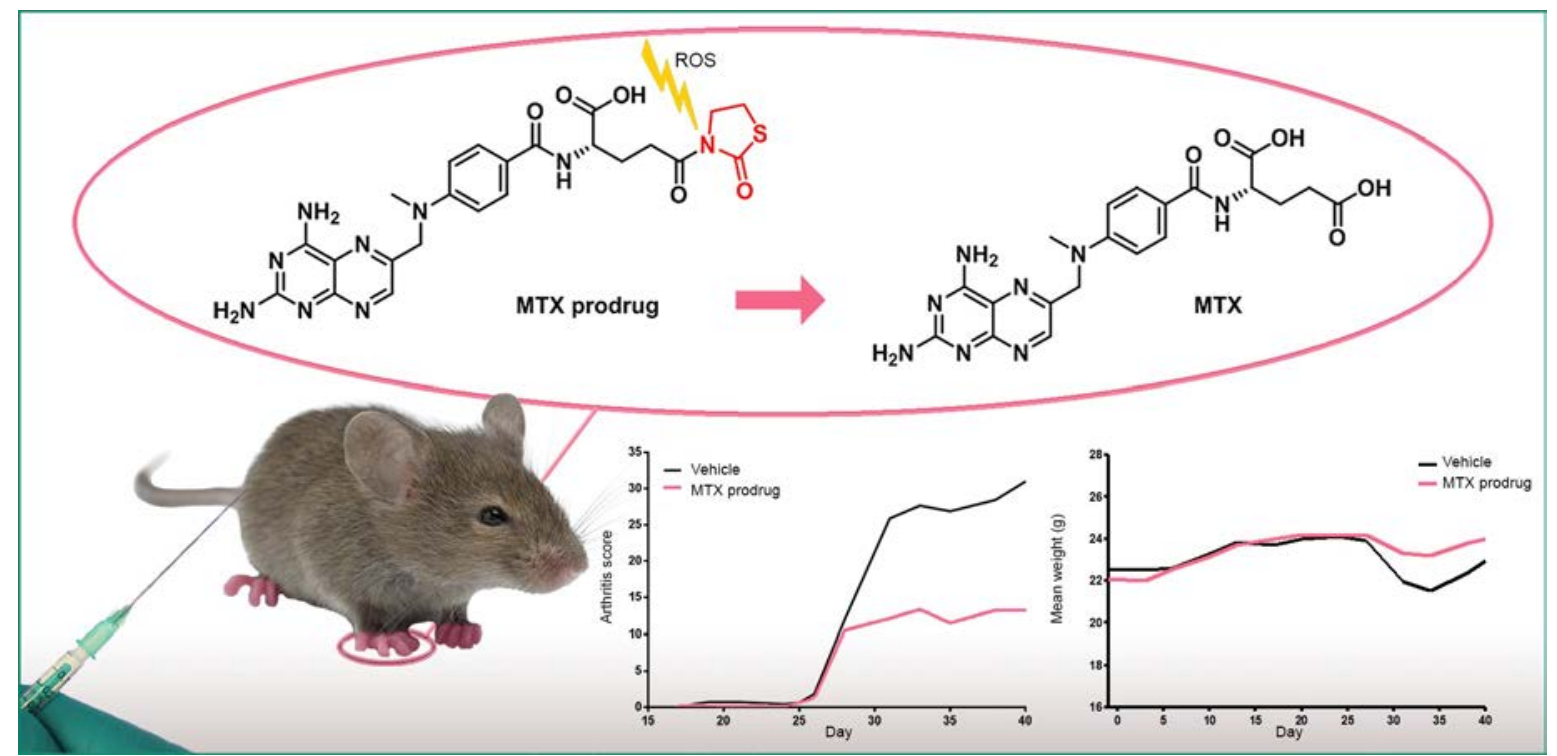

Keywords:

Rheumatoid arthritis, inflammation, methotrexate, prodrug, thiazolidinone, reactive oxygen species. 


\section{Chemical compounds studied in this article:}

Methotrexate (PubChem CID: 126941)

\section{Abbreviations}

ADMET, absorption, distribution, metabolism, excretion, toxicity; CFA, Complete Freund’s Adjuvant; CIA, collagen-induced arthritis; CL' ${ }_{\text {int, }}$ apparent intrinsic clearance; DBA, dilute brown non-agouti; dec., decompose; DMA, dimethylacetamide; DMARD, disease-modifying antirheumatic drug; HD, high-dose; i.p., intraperitoneal; LD, low-dose; MTX, methotrexate; PBS, phosphate buffered saline; RA, rheumatoid arthritis; ROS, reactive oxygen species; SEM, standard error of the mean; TNF, tumor necrosis factor; TZ, 1,3thiazolidin-2-one. 


\section{Introduction}

\subsection{Background}

Rheumatoid arthritis (RA) is a common autoimmune disease characterized by chronic synovial inflammation and is associated with progressive disability, systemic complications, early death, and socioeconomic costs [1]. The pathogenesis of RA is still incompletely understood but involves a complex interplay of genetic and environmental factors. It is estimated that $0.5-1 \%$ of the adult populations in developed countries suffer from RA, with a prevalence three times greater for women than men [2].

Currently, no cure for RA exists and treatment strategies consist of life-long palliative care, primarily using disease-modifying antirheumatic drugs (DMARDs) to relieve inflammatory symptoms and retard joint destruction. Since the 1980s, methotrexate (MTX, 1) has been the standard of care in the treatment of RA (Figure 1). MTX was originally developed as a folic acid antagonist for high-dose cancer therapy (HD-MTX: 1,000-5000 mg/week). However, low-dose treatment (LD-MTX: 5-25 mg/week), administered either orally, subcutaneously, or intravenously, has shown potent anti-inflammatory effects in patients suffering from RA [3-5].<smiles>CN(Cc1cnc2nc(N)nc(N)c2n1)c1ccc(C(=O)N[C@@H](CCC(=O)O)C(=O)O)cc1</smiles>

Figure 1. Methotrexate (1) is the standard of care for treament of RA.

Unfortunately, in spite of LD-MTX being the standard of care in managing RA, treatment is still unsatisfactory for many patients. Low-dose treatment is associated with several prominent adverse effects, in particular gastrointestinal toxicities but also hepatotoxicity, lethargy, fatigue, nodulosis, hepatic and pulmonary fibrosis, 
renal insufficiency, anemia, and neutropenia [4]. Furthermore, LD-MTX suffers from high interindividual variability, leading to unpredictable treatment outcomes and, in many cases, poor patient response or lack of efficacy $[4,6]$. Consequently, nearly half of patients discontinue treatment within 3 years of therapy [7]. Currently, the best alternative is combinational therapy using MTX with newer biological therapeutics such as the anti-TNF- $\alpha$ agents etanercept or infliximab. However, such treatments are extremely costly and are associated with additional side effects [3,4]. Thus, there is still an urgent need for improving the efficacy and safety of RA therapies.

Prodrugs are inactive forms of pharmaceuticals that undergo chemical or enzymatic conversion in vivo to release the active agent [8-10]. Prodrug design is typically implemented to improve undesirable absorption, distribution, metabolism, excretion, toxicity (ADMET) properties, typically poor solubility or absorption, but it may also be exploited to increase tissue selectivity. While several prodrugs, drug conjugates, and drug delivery systems for MTX have been reported in the literature over the years, so far none have been approved for clinical use [11].

Reactive oxygen species (ROS), e.g. $\mathrm{H}_{2} \mathrm{O}_{2}, \mathrm{O}_{2}{ }^{-}, \mathrm{HO}^{*}$, and $\mathrm{HOCl}$, serve important physiological roles that include signaling functions, host defense, and oxidative biosynthesis [12,13]. However, elevated levels of ROS can lead to harmful oxidative stress, which is a central component of the pathogenesis of chronic inflammation [14-17], including autoimmune disease such as RA [18,19]. $\mathrm{H}_{2} \mathrm{O}_{2}$ is the most stable of the ROS and under pathological conditions, extracellular concentrations up to $1 \mathrm{mM}$ of $\mathrm{H}_{2} \mathrm{O}_{2}$ have been measured [12,20-23]. This increased concentration of $\mathrm{H}_{2} \mathrm{O}_{2}$ can potentially serve as a stimulus for site-selective drug delivery of ROS sensitive prodrugs. Development of such prodrugs has emerged as a novel approach to potentially increase target selectivity of drugs. Examples of $\mathrm{H}_{2} \mathrm{O}_{2}$ sensitive promoieties include phenylboronic acids and esters [24-29], phenylsulfonate esters [30,31], $N$-(2,5-dihydroxyphenyl)acetamides [32], $\alpha$-boryl ethers, carbonates, and acetals [33], and 1,3-thiazolidin-2-one has also been proposed as a promising ROS labile promoiety [34].

Recently, our group published promising preliminary results for the treatment of RA using a boronic acid based MTX prodrug in vivo [35]. Based on these results and the promising ROS sensitive properties of the 
1,3-thiazolidin-2-one moiety (henceforward simply thiazolidinone or TZ), we here propose a new strategy for the treatment of RA using a thiazolidinone-based MTX prodrug for site-selective delivery of MTX. Our aim is to localize and accumulate MTX in inflammatory tissue in order to improve the safety profile and potentially the efficacy of the drug. We herein report the synthesis, in vitro pharmacokinetic and physiochemical studies, and in vivo evaluation in a murine collagen-induced arthritis (CIA) model.

\subsection{Strategy}

The thiazolidinone group can be introduced through coupling to a carboxylic acid. As MTX contains two carboxylic acids ( $\alpha$ and $\gamma$ ), we planned at first, to synthesize three MTX prodrugs: MTX- $\alpha$-TZ (2), MTX- $\gamma$-TZ (3), and $\mathrm{MTX}-\mathrm{TZ}_{2}$ (4) to explore the potentially different behavior of the compounds (Figure 2).

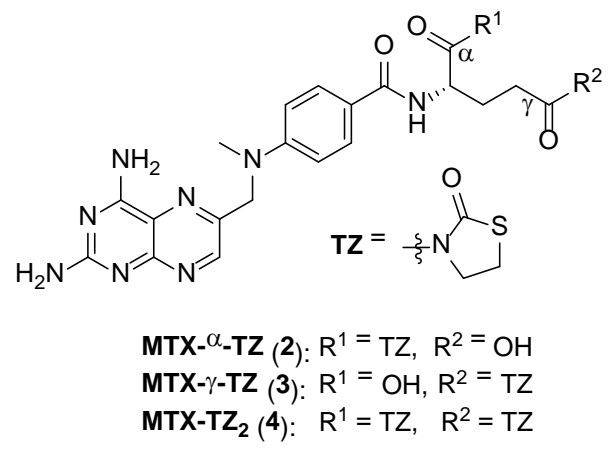

Figure 2: The three targeted thiazolidinone (TZ) based MTX prodrug candidates: Methotrexate- $\alpha$ thiazolidinone (MTX- $\alpha-\mathrm{TZ}, 2$ ), methotrexate- $\gamma$-thiazolidinone (MTX- $\gamma-\mathrm{TZ}, 3$ ), and methotrexate- $\alpha, \gamma-$ dithiazolidinone (MTX-TZ2, 4). 


\section{Results and discussion}

\section{$2.1 \quad M T X-\mathrm{TZ}_{2}(4)$}

\subsubsection{Synthesis}

As a preliminary test of the hypothesis, $\mathrm{MTX}-\mathrm{TZ}_{2}(\mathbf{4})$ was initially synthesized to investigate its properties for use as a prodrug. Starting from commercially available MTX, MTX-TZ 2 was obtained in one step using DCC and DMAP for the coupling (Scheme 1).
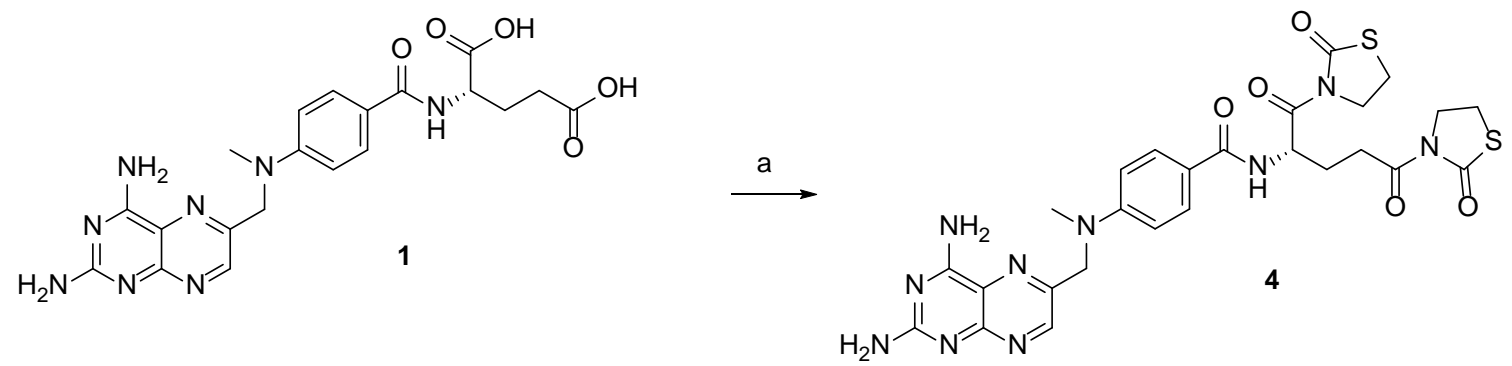

Scheme 1: Synthesis of MTX-TZ2. Reagents and conditions: (a) Thiazolidin-2-one, DCC, DMAP, DMF, 16 h (18\%).

\subsubsection{Preliminary evaluation of prodrug stability}

As a first measure of prodrug potential, the aqueous stability of the synthesized prodrug candidate was examined in PBS (pH 7.4) at $20^{\circ} \mathrm{C}$ using RP-UPLC-MS analysis. Interestingly, the $\alpha$-thiazolidinone moiety of MTX-TZ 2 (4) was highly labile and rapidly hydrolyzed to release MTX- $\gamma-\mathrm{TZ}$ (3) within 30 minutes (Figure S1, SI). On the other hand and to our delight, MTX- $\gamma$-TZ (3) was significantly more stable and no hydrolysis of this compound was observed even after $24 \mathrm{~h}$. Based on the short half-life of the $\alpha$-thiazolidinone moiety, MTX- $\alpha$-TZ (2) was deemed to likely be a poor prodrug candidate and we decided to pursue MTX- $\gamma$-TZ as the most promising of the three thiazolidinone-based MTX prodrugs shown in Figure 2. 


\subsubsection{Synthesis}

MTX- $\gamma$-TZ (3) was synthesized from the commercially available pteridine alcohol 5 (Scheme 2). The commercially available hydrochloride salt of $\mathbf{5}$ was first neutralized with aqueous $\mathrm{NaOH}$ and then converted to the corresponding $\alpha$-bromo species in situ using $\mathrm{PPh}_{3} \mathrm{Br}_{2}$ followed by nucleophilic substitution with 4(methylamino)benzoic acid to form 6. Coupling of $\mathrm{H}-\mathrm{Glu}(\mathrm{OMe})-\mathrm{O}$ Bu with 6 using PyBOP and $\mathrm{Et}_{3} \mathrm{~N}$ with subsequent hydrolysis of the $\gamma$-methyl ester using $\mathrm{Ba}(\mathrm{OH})_{2}$, afforded MTX- $\alpha$-OtBu (7). The thiazolidinone moiety was then introduced to the $\gamma$ position through a DCC/DMAP-mediated coupling with the unprotected $\gamma$-carboxylic acid to obtain compound 8. Finally, $\alpha$-tert-butyl ester deprotection was achieved in neat formic acid to give the desired MTX- $\gamma$-TZ (3) in reasonable yield (74\%) and excellent purity (>95\%) after preparative HPLC.<smiles>CCOC(=O)C(CCC(=O)O)NC(=O)c1ccc(N(C)Cc2cnc3nc(N)nc(N)c3n2)cc1</smiles>
5<smiles>CCOC(=O)C(CCC(=O)N1CCSC1=O)NC(=O)c1ccc(N(C)Cc2cnc3nc(N)nc(N)c3n2)cc1</smiles>

Scheme 2: Synthesis of MTX- $\gamma$-TZ (3). Reagents and conditions: (a) $\mathrm{NaOH} / \mathrm{H}_{2} \mathrm{O}, 80{ }^{\circ} \mathrm{C}, 5$ min. (b) $\mathrm{PPh}_{3} \mathrm{Br}_{2}, \mathrm{DMA}_{\text {, }}$ 20 h, then 4-(methylamino)benzoic acid, DIPEA, 72 h (90\%). (c) PyBOP, $\mathrm{Et}_{3} \mathrm{~N}, \mathrm{DMF}, 16 \mathrm{~h}$. (d) $\mathrm{Ba}(\mathrm{OH})_{2}, \mathrm{H}_{2} \mathrm{O} / \mathrm{EtOH}$, 16 h (79\%). (e) thiazolidin-2-one, DCC, DMAP, DMF, 16 h (65\%). (f) $\mathrm{HCO}_{2} \mathrm{H}, 20$ h (74\%). 


\subsection{Physiochemical and pharmacokinetic evaluation}

\subsubsection{Prodrug activation under oxidative conditions and PBS stability}

Activation of MTX- $\gamma$-TZ (3) was examined in vitro under different concentrations of $\mathrm{H}_{2} \mathrm{O}_{2}(10-5-1-0.5-$ $0.25 \mathrm{mM}$ ) in $20 \%$ DMSO/PBS at $37^{\circ} \mathrm{C}$ and was followed by RP-UPLC-MS (Figure 3, left). Diclofenac was used as internal standard and its stability in a solution of $\mathrm{H}_{2} \mathrm{O}_{2}$ was confirmed (Figure S2, SI). Importantly, MTX was confirmed to be the product of prodrug activation (Figure S3, SI, top left and top right) and to be stable under different concentrations of $\mathrm{H}_{2} \mathrm{O}_{2}$ (10 and $0 \mathrm{mM}$, Figure S3, SI, bottom). The prodrug half-life at $5 \mathrm{mM}$ was determined to be $1.7 \pm 0 \mathrm{~h}$. As expected, the rate of activation was dependent on the concentration of $\mathrm{H}_{2} \mathrm{O}_{2}$ and at $0.5 \mathrm{mM} \mathrm{H}_{2} \mathrm{O}_{2}$, the half-life was reduced to $16.5 \pm 0 \mathrm{~h}$. Figure 3 (right) shows the appearance of MTX as a consequence of the activation of MTX- $\gamma$-TZ (3) within the first hour of the experiment. MTX reached $50 \%$ with $10 \mathrm{mM} \mathrm{H}_{2} \mathrm{O}_{2}$ and at patho-physiological concentrations of $\mathrm{H}_{2} \mathrm{O}_{2}(0.5 \mathrm{mM})$, MTX formed at around 7\%. To evaluate the rate of non- $\mathrm{H}_{2} \mathrm{O}_{2}$-mediated hydrolysis, the aqueous stability of MTX- $\gamma$-TZ (3) under the same conditions (20\% DMSO/PBS at $37^{\circ} \mathrm{C}$ ) was also examined. Here, MTX- $\gamma$-TZ (3) exhibited excellent stability with a half-life of $115.5 \pm 0 \mathrm{~h}$ indicating that release of MTX is primarily driven by hydrogen peroxide activation of the prodrug.
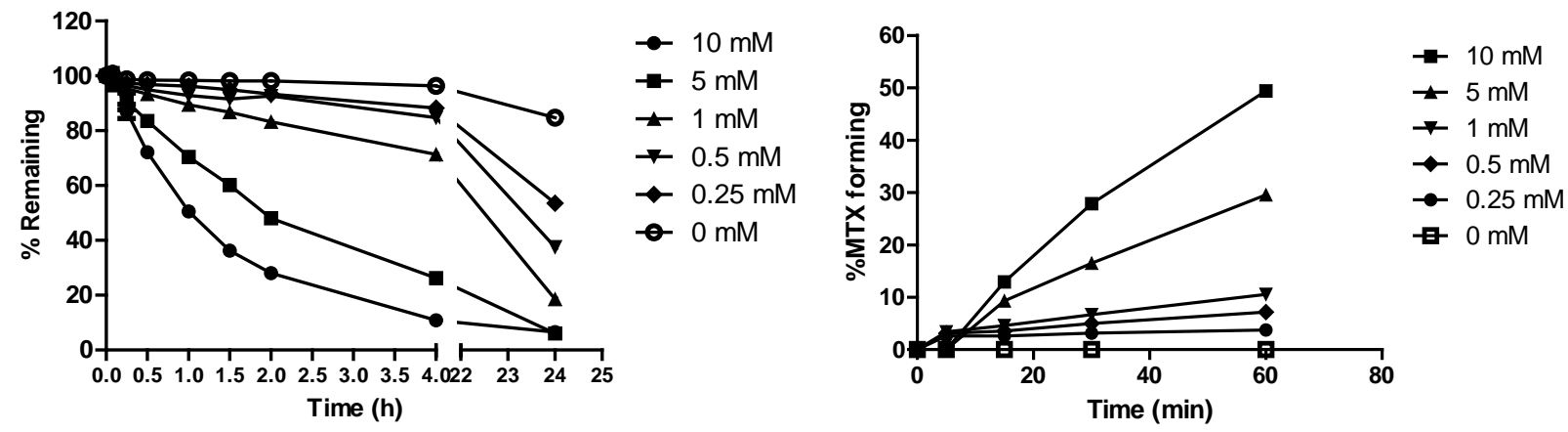
Figure 3: Activation of prodrug MTX- $\gamma$-TZ (3) (left) and appearance of MTX (right) in the presence of varying concentrations of $\mathrm{H}_{2} \mathrm{O}_{2}$. The experiments were carried out at a compound concentration of $100 \mu \mathrm{M}$ in a mixture of $20 \%$ DMSO in PBS at $37^{\circ} \mathrm{C}$. Experiments were performed in triplicates $(\mathrm{n}=3)$ and analyzed by RP-UPLCMS $(\lambda=306 \mathrm{~nm})$ using diclofenac as internal standard. Error bars are calculated as the standard deviation. Hidden error bars are smaller than symbols.

To further evaluate the drug-like properties of MTX- $\gamma$-TZ (3), the prodrug candidate was subjected to a series of pharmacokinetic and physiochemical assays (Table 1).

\subsubsection{Plasma stability}

Plasma stability was examined in reconstituted freeze dried human plasma diluted 1:1 with PBS to ensure a $\mathrm{pH}$ of 7.4 [36]. At $37^{\circ} \mathrm{C}$, the half-life of MTX- $\boldsymbol{\gamma}$-TZ was determined as $7 \pm 1 \mathrm{~h}$ indicating good plasma stability [37] (Table 1 and Figure S4, SI).

\subsubsection{Metabolic stability}

Metabolic stability was evaluated by determining the apparent intrinsic clearances ( $\left.\mathrm{CL}^{\prime}{ }_{\mathrm{int}}\right)$ in human pooled liver microsomes. The apparent intrinsic clearance was calculated to be $1.4 \pm 0.4 \mathrm{~mL} / \mathrm{min} / \mathrm{kg}$ indicating excellent metabolic stability [38] (Table 1 and Figure S5, SI).

\subsubsection{Thermodynamic solubility}

The thermodynamic solubility of MTX- $\gamma$-TZ was measured in PBS at $20^{\circ} \mathrm{C}$ and determined as $400 \pm 50 \mu \mathrm{g} / \mathrm{mL}$ (Table 1 and Figure S6, SI). This is considered high solubility according to guidelines for oral administration in humans and animal dosing formulations [39]. 
Table 1: Pharmacokinetic and physiochemical properties of prodrug candidate MTX- $\gamma$-TZ (3). Values are an average of at least three measurements \pm standard deviation (SD), unless otherwise stated.

\begin{tabular}{|c|c|c|c|c|c|}
\hline $\begin{array}{l}\text { Solubility } \\
(\mu \mathrm{g} / \mathrm{mL})^{\mathrm{a}}\end{array}$ & $\begin{array}{c}\text { Human } \\
\text { plasma stab. } \\
\mathbf{t}_{1 / 2}(\mathbf{h})^{\mathbf{b}}\end{array}$ & $\begin{array}{c}\text { PBS stab. } \\
t_{1 / 2}(\mathbf{h})^{b}\end{array}$ & $\begin{array}{c}\text { Metabolic } \\
\text { stability, CL'int } \\
\text { (mL/min/kg) }\end{array}$ & $\begin{array}{c}5 \mathrm{mM} \mathrm{H}_{2} \mathrm{O}_{2} \\
\text { activation } \\
\mathbf{t}_{1 / 2}(\mathbf{h})^{b}\end{array}$ & $\begin{array}{c}0.5 \mathrm{mM} \mathrm{H}_{2} \mathrm{O}_{2} \\
\text { activation } \\
\mathbf{t}_{1 / 2}(\mathbf{h})^{\mathbf{b}}\end{array}$ \\
\hline $400 \pm 50$ & $7 \pm 1.0$ & $115.5 \pm 0.01$ & $1.4 \pm 0.4$ & $1.7 \pm 0.01$ & $16.5 \pm 0.01$ \\
\hline
\end{tabular}

2.4 In vivo anti-arthritic efficacy and preliminary toxicity

Based on the promising in vitro physiochemical and pharmacokinetic data, MTX- $\gamma$-TZ (3) was tested for antiinflammatory activity in vivo using a murine collagen-induced arthritis (CIA) model. This model was chosen as it has been extensively studied using many agents including MTX [40], and is known to have the best record of predictability across species as compared to other in vivo arthritis models [41,42]. A dosing regime equimolar to $7 \mathrm{mg} / \mathrm{kg}$ MTX with daily intraperitoneal (i.p.) administration was selected. To minimize antiinflammatory effects of DMSO [43,44], the concentration of DMSO was kept to 2\% (v/v).

Therapeutic intervention was initiated at the onset of disease, 27 days after induction of chronic and destructive arthritis using type-II collagen (CII) in Complete Freund's Adjuvant (CFA), and treatment was prolonged for 14 days. Disease evaluation was based on a macroscopic scoring system and performed three times a week (see Figure 4). As evident from the figure, MTX- $\gamma$-TZ (3) showed comparable efficacy to MTX while both compounds effectively reduced the severity of arthritis compared to the vehicle. 


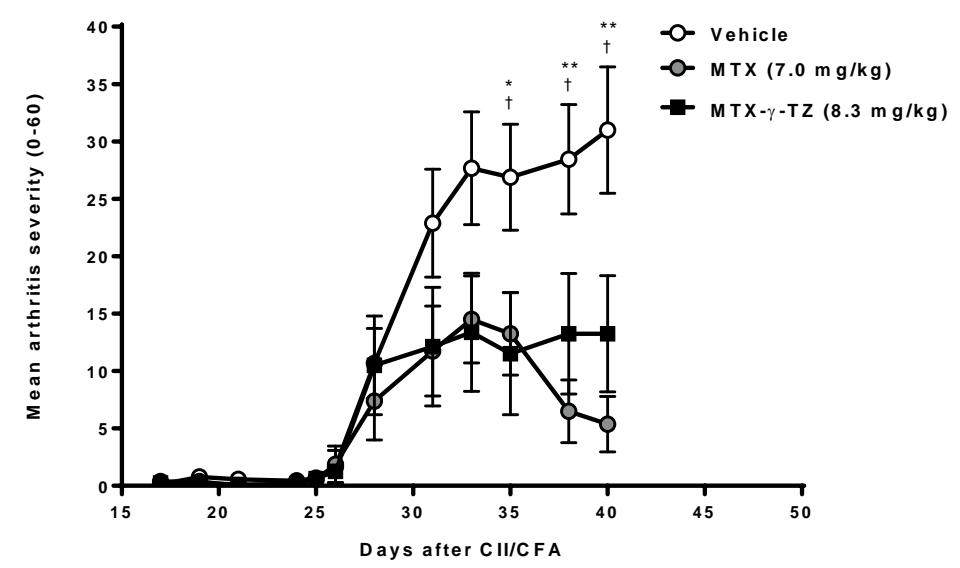

Figure 4: Suppression of CIA development in mice after treatment with MTX (7 mg/kg), MTX- $\gamma$-TZ (8.3 $\mathrm{mg} / \mathrm{kg}$ ), and vehicle ( $\mathrm{n}=8$ per group). DBA/1J mice were given the indicated amounts of compound daily, starting at onset of disease (day 27), and disease progression was evaluated three times per week. A macroscopic scoring system of the four limbs 2ranging from 0 to 15 (1 point per swollen toe, 1 point per swollen foot knuckle, and 5 points for swollen ankle) was used for a maximal score of 60 per mouse. One animal in the vehicle group was sacrificed pre-termination due to high arthritis severity score. Data represents mean values of arthritic score \pm SEM. * represents a p-value $<0.05$ and ${ }^{* *}$ represents a p-value $<0.01$ when comparing MTX and vehicle groups while † represents a p-value $<0.05$ between MTX- $\gamma$-TZ (3) and vehicle. Statistics were calculated using a one-tailed nonparametric Mann-Whitney.

As a first estimate of drug tolerability, the general health of the mice was evaluated as a function of body weight (Figure 5). While the MTX group suffered from a reduction in body weight towards the end of the study, mice being treated with MTX- $\gamma$-TZ (3) experienced a significantly more stable body weight compared to the MTX group, indicating a safer toxicity profile.

Compared to recently published results for the in vivo effects of a boronic acid based MTX prodrug [35], MTX- $\gamma$-TZ (3) shows very comparable behavior in the murine CIA model, both with regards to efficacy and mean body weight of the treated mice. 


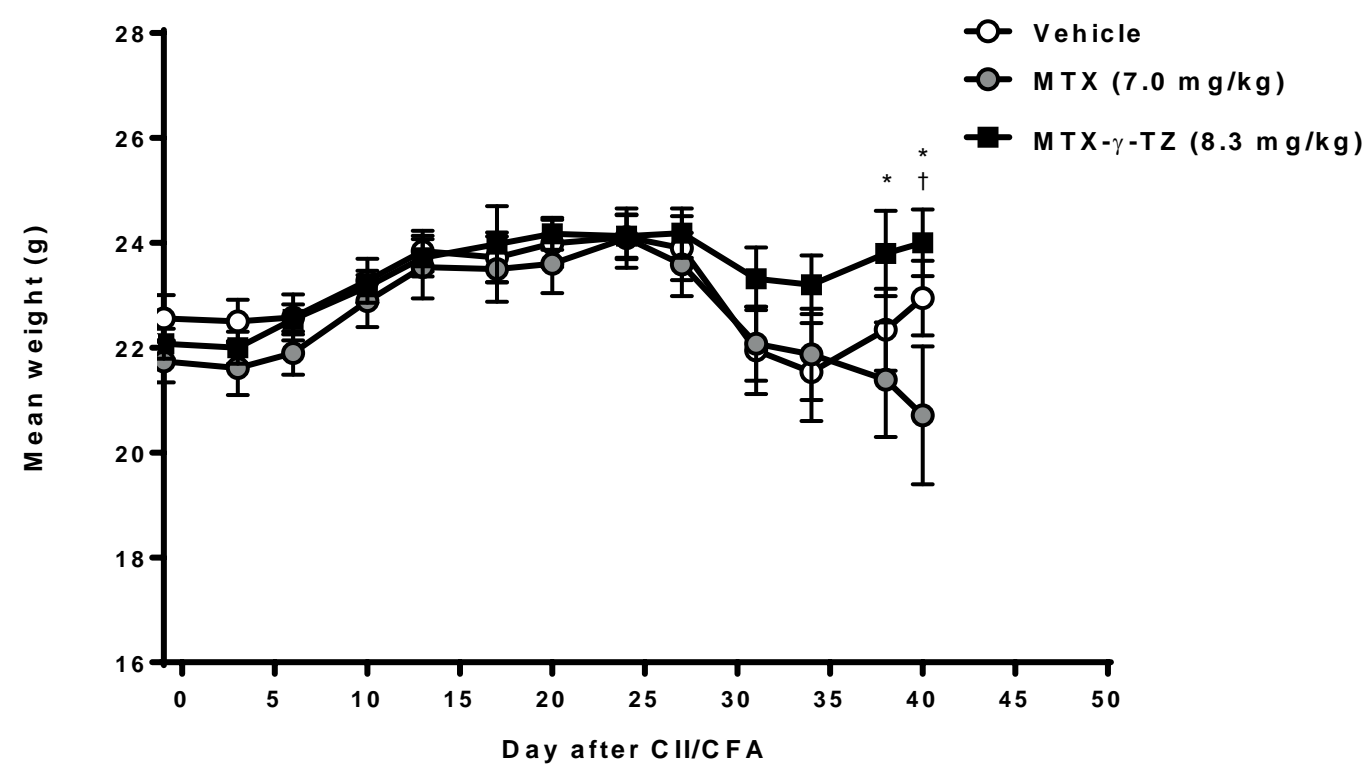

Figure 5: The general health of mice was evaluated as the average body weight during collagen-induced arthritis as an indication of drug tolerability. Measurements were performed three times per week $(\mathrm{n}=8$ per group). One animal in the vehicle group was sacrificed pre-termination due to high arthritis severity score. Data represents mean values of body weight \pm SEM. * represents a p-value $<0.05$ when comparing MTX and MTX- $\gamma$-TZ (3) while $†$ represents a p-value $<0.05$ between MTX and vehicle. Statistics were calculated using a one-tailed nonparametric Mann-Whitney.

\section{Conclusion}

Of the two thiazolidinone-based MTX prodrugs that were synthesized for targeted treatment of inflammatory tissue in RA, MTX- $\gamma$-TZ (3) had the most promising properties. While the $\alpha$-thiazolidinone of MTX-TZ showed poor stability in aqueous media, MTX- $\gamma$-TZ (3) was selectively activated at patho-physiological concentrations of $\mathrm{H}_{2} \mathrm{O}_{2}$. This prodrug candidate displayed excellent chemical stability in PBS, good stability in human plasma, excellent metabolic stability, and excellent aqueous solubility. In vivo, MTX- $\gamma$-TZ (3) 
exhibited comparable efficacy to the standard of care, MTX, in a murine CIA model. Mice being treated with MTX- $\gamma$-TZ (3) experienced a significantly more stable body weight compared to the MTX group, indicating reduced toxicity. These preliminary results show promise in improving the treatment of RA and future work will focus on additional in vivo studies to establish optimal dosing and to further investigate the toxicity profile.

\section{Materials and methods}

\subsection{Chemistry}

Thiazolidin-2-one was obtained from Fluorochem Ltd. All other starting materials, reagents, and solvents were purchased from Sigma-Aldrich and used without further purification. All reactions were run under a $\mathrm{N}_{2}$ atmosphere and were monitored by thin layer chromatography (TLC) and/or reversed-phase ultra-performance liquid chromatography mass spectrometry (RP-UPLC-MS).

Analytical TLC was conducted on Merck aluminum sheets covered with silica (C60). The plates were either visualized under UV-light or stained by dipping in a developing agent followed by heating. $\mathrm{KMnO}_{4}$ [3 $\mathrm{g}$ in water (300 mL) along with $\mathrm{K}_{2} \mathrm{CO}_{3}(20 \mathrm{~g})$ and $5 \%$ aqueous $\mathrm{NaOH}(5 \mathrm{~mL})$ ] were used as developing agent. Flash column chromatography was performed using Merck Geduran ${ }^{\circledR}$ Si 60 (40-63 $\left.\mu \mathrm{m}\right)$ silica gel. For the recording of ${ }^{1} \mathrm{H}$ NMR and ${ }^{13} \mathrm{C}$ NMR a Bruker Ascend equipped with a Prodigy cryoprobe (operating at 400 MHz for proton and $101 \mathrm{MHz}$ for carbon) was used. The chemical shifts ( $\delta$ ) are reported in parts per million (ppm) and the coupling constants $(J)$ in Hz. For spectra recorded in DMSO- $d_{6}$, signal positions were measured relative to the signal for DMSO ( $\delta 2.50 \mathrm{ppm}$ for ${ }^{1} \mathrm{H}$ NMR and $\delta 39.43 \mathrm{ppm}$ for ${ }^{13} \mathrm{C}$ NMR). For spectra recorded in $\mathrm{CDCl}_{3}$, signal positions were measured relative to the signal for $\mathrm{CHCl}_{3}\left(\delta 7.26 \mathrm{ppm}\right.$ for ${ }^{1} \mathrm{H}$ NMR and $\delta 77.0$ ppm for ${ }^{13} \mathrm{C}$ NMR). IR analysis was performed on a Bruker Alpha FT-IR spectrometer. Analytical RP-UPLCMS (ESI) analysis was performed on a S2 Waters AQUITY RP-UPLC system equipped with a diode array detector using an Thermo Accucore C18 column (d $2.6 \mu \mathrm{m}, 2.1$ x $50 \mathrm{~mm}$; column temp: $50{ }^{\circ} \mathrm{C}$; flow: 1.0 
$\mathrm{mL} / \mathrm{min})$. Eluents $\mathrm{A}\left(0.1 \% \mathrm{HCO}_{2} \mathrm{H}\right.$ in $\left.\mathrm{H}_{2} \mathrm{O}\right)$ and $\mathrm{B}\left(0.1 \% \mathrm{HCO}_{2} \mathrm{H}\right.$ in $\left.\mathrm{MeCN}\right)$ were used in a linear gradient (5\% B to $100 \%$ B) in 2.4 min and then held for 0.1 min at 100\% B (total run time: $2.6 \mathrm{~min}$ ). The LC system was coupled to a SQD mass spectrometer. RP-UPLC-UV method validation is reported in the Supporting Information. Analytical LC-HRMS (ESI) analysis was performed on an Agilent 1100 RP-LC system equipped with a diode array detector using a Phenomenex Luna C18 column (d $3 \mu \mathrm{m}$, 2.1 x 50 mm; column temp: 40 ${ }^{\circ} \mathrm{C}$; flow: $\left.0.4 \mathrm{~mL} / \mathrm{min}\right)$. Eluents $\mathrm{A}\left(0.1 \% \mathrm{HCO}_{2} \mathrm{H}\right.$ in $\left.\mathrm{H}_{2} \mathrm{O}\right)$ and $\mathrm{B}\left(0.1 \% \mathrm{HCO}_{2} \mathrm{H}\right.$ in $\left.\mathrm{MeCN}\right)$ were used in a linear gradient (20\% B to $100 \%$ B) in a total run time of $15 \mathrm{~min}$. The LC system was coupled to a Micromass LCT orthogonal time-of-flight mass spectrometer equipped with a Lock Mass probe operating in positive electrospray mode. Optical rotation was carried out using a Perkin-Elmer polarimeter 341. The temperature for all recordings was approximately $20^{\circ} \mathrm{C}$. Melting points were obtained using a Stuart SMP30 melting point apparatus and are uncorrected. Preparative RP-HPLC was carried out on a Waters Alliance reversed-phase HPLC system consisting of a Waters 2545 Binary Gradient Module equipped with either an xBridge BEH C18

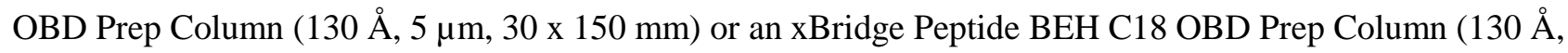
$5 \mu \mathrm{m}, 19 \mathrm{~mm} \times 100 \mathrm{~mm}$ ) both operating at $20^{\circ} \mathrm{C}$ and a flow rate of $20 \mathrm{~mL} / \mathrm{min}$, a Waters Photodiode Array Detector (detecting at 210-600 nm), a Waters UV Fraction Manager, and a Waters 2767 Sample Manager. Eluents A $\left(0.1 \% \mathrm{HCO}_{2} \mathrm{H}\right.$ in $\left.\mathrm{H}_{2} \mathrm{O}\right)$ and $\mathrm{B}\left(0.1 \% \mathrm{HCO}_{2} \mathrm{H}\right.$ in $\left.\mathrm{MeCN}\right)$ were used in the following gradient: $5 \% \mathrm{~B}$ to $70 \%$ B in 10 min, hold for 3.5 min, then $70 \%$ B to $100 \%$ B in 1.5 min, and hold 3 minutes (total run time: $20 \mathrm{~min}$ ). The purity of the compounds was assessed by RP-UPLC-UV and NMR, and purities $\geq 95 \%$ were considered acceptable for evaluation purposes both in in vitro and in vivo assays. 


\subsection{Synthesis}

\subsection{1 (S)-4-((2,4-Diaminopteridin-6-yl)methyl)(methyl)amino)- $N$-(1,5-dioxo-1,5-bis(2-oxothiazolidin-3-}

yl)pentan-2-yl)benzamide (4)

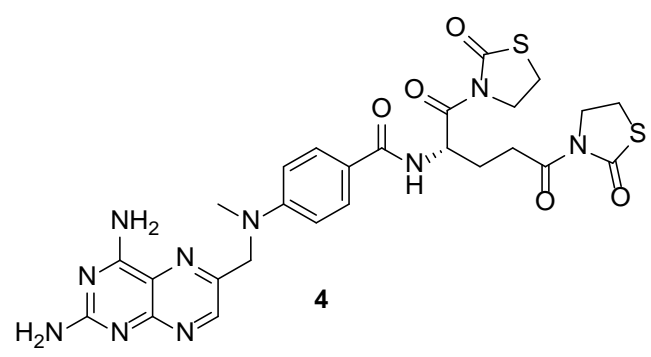

To a solution of MTX (209 mg, $0.460 \mathrm{mmol}$ ) in anhydrous DMF (5 mL) were added DCC (209 mg, 1.01 mmol) and DMAP (124 mg, $1.01 \mathrm{mmol}$ ) and the turbid reaction mixture was stirred for $20 \mathrm{~min}$ at $20{ }^{\circ} \mathrm{C}$. Thiazolidin-2-one (95.1 mg, $0.922 \mathrm{mmol}$ ) was added and the turbid mixture was stirred overnight. The precipitate was removed by filtration and the filtrate was purified by preparative HPLC to give the desired product 4 as a yellow solid (53.1 mg, $18 \%)$. mp: > $151{ }^{\circ} \mathrm{C}($ dec. $) ;[\alpha]_{\mathrm{D}}^{20}=+1.8^{\circ}\left(c 0.73\right.$, DMSO); ${ }^{1} \mathrm{H}$ NMR $(400$ MHz, DMSO-d $\left.d_{6}\right) \delta 8.57$ (s, 1H), 8.25 (d, $J=7.3 \mathrm{~Hz}, 1 \mathrm{H}$ ), 7.72 (d, $J=8.9 \mathrm{~Hz}, 2 \mathrm{H}$ ), 7.65 (br. s, 1H), 7.43 (br. s, 1H), 6.82 (d, $J=9.0 \mathrm{~Hz}, 2 \mathrm{H}), 6.61$ (br. s, 2H), 5.28 (q, $J=7.0 \mathrm{~Hz}, 1 \mathrm{H}), 4.78$ (s, 2H), 4.14 - 3.98 (m, 4H), 3.40 (t, $J=7.3 \mathrm{~Hz}, 2 \mathrm{H}), 3.33$ (td, $J=7.2,2.5 \mathrm{~Hz}, 2 \mathrm{H}), 3.21$ (s, 3H), 2.98 (dt, $J=17.6,7.5 \mathrm{~Hz}, 1 \mathrm{H}), 2.81$ (dt, $J$ = 17.6, 7.6 Hz, 1H), 1.98 (q, $J=7.2 \mathrm{~Hz}, 2 \mathrm{H}) ;{ }^{13} \mathrm{C}$ NMR (101 MHz, DMSO-d 6 ) $\delta$ 173.4, 173.2, 172.8, 172.0, 167.0, 163.4, 163.2, 155.6, 151.5, 149.6, 146.4, 129.5, 121.2 (2C), 111.5, 55.3, 52.8, 47.7, 47.4, 40.6, 33.9, 25.7, 25.6, 25.3; IR (neat) $\mathrm{cm}^{-1}$ : 3344, 3325, 3066, 3034, 2953, 2924, 1702, 1644, 1236, 1153; HRMS (ESI) calcd. for $\left[\mathrm{C}_{26} \mathrm{H}_{29} \mathrm{~N}_{10} \mathrm{O}_{5} \mathrm{~S}_{2}\right][M+\mathrm{H}]^{+}$625.1758, found 625.1779. 


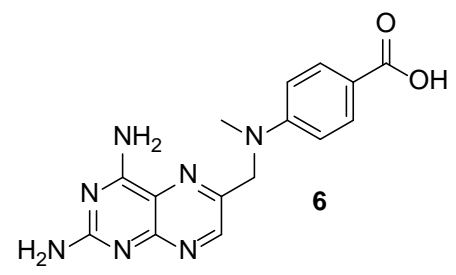

Synthesis was performed following a published procedure [45]. Pteridine alcohol 5 hydrochloride (3.34 g, 14.6 mmol) was dissolved in hot water $(120 \mathrm{~mL})$ and the solution was left to cool to $20{ }^{\circ} \mathrm{C}$. The solution was neutralized with $1 \mathrm{M} \mathrm{NaOH}$ (ca. $12 \mathrm{~mL}$ ) and the precipitate was collected by filtration, washed with water, and dried in vacuo over $\mathrm{P}_{2} \mathrm{O}_{5}$. The orange-beige solid was suspended in anhydrous DMA (20 mL) and triphenylphosphine dibromide (13.9 g, $32.9 \mathrm{mmol})$ was then added. The turbid reaction mixture was stirred for $20 \mathrm{~h}$ at $20^{\circ} \mathrm{C}$ and 4-(methylamino)benzoic acid (2.45 g, $16.2 \mathrm{mmol}$ ) and DIPEA (5.34 mL, $30.7 \mathrm{mmol}$ ) were added. The turbid mixture was stirred for another 3 days at $20^{\circ} \mathrm{C}$ and then poured into $0.33 \mathrm{M} \mathrm{NaOH}$ (190 $\mathrm{mL}$ ). The precipitate was filtered off and the filtrate was acidified to approximately $\mathrm{pH} 4.5$ with $10 \% \mathrm{AcOH}$ in water (ca. $20 \mathrm{~mL}$ ). The precipitate was collected by filtration, washed with water, triturated with hot methanol (23 mL), and dried in vacuo over $\mathrm{P}_{2} \mathrm{O}_{5}$ to give the title compound as an orange-beige solid (4.25g, 90\%). ${ }^{1} \mathrm{H}$ NMR (400 MHz, DMSO-d6) $\delta 12.2$ (br. s, 1H), 8.66 (s, 1H), 8.42 (br. s, 1H), 8.19 (br. s, 1H), 7.73 (d, J = 9.0 Hz, 2H), 7.21 (br. s, 2H), 6.83 (d, J = $9.1 \mathrm{~Hz}, 2 \mathrm{H}), 4.83$ (s, 2H), 3.24 (s, 3H), (Litt. [45]). ${ }^{13} \mathrm{C}$ NMR (101 MHz, DMSO-d6) $\delta$ 167.4, 162.7, 159.5, 151.8, 150.7, 148.9, 148.2, 131.0, 121.9, 117.7, 111.2, 54.8, 39.2. IR (neat) cm-1: 3341, 3189, 2956, 2823, 1660, 1599, 1294, 1188 (Litt. [45]). 

oxopentanoic acid (7)

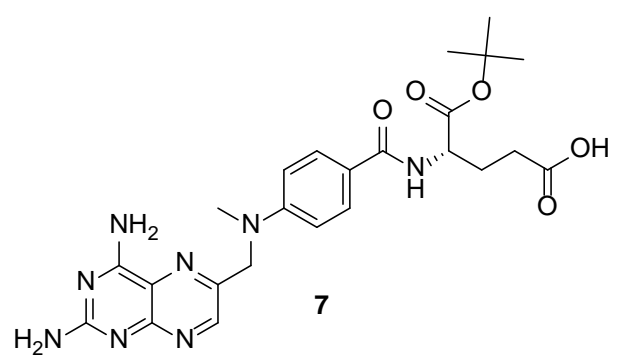

To a solution of pteroic acid 6 (3.15 g, $8.71 \mathrm{mmol}$, 90\% purity) in anhydrous DMF (200 mL) were added PyBOP (6.55 g, $12.6 \mathrm{mmol})$ and triethylamine $(6.00 \mathrm{~mL}, 45.2 \mathrm{mmol})$ and the turbid reaction mixture was stirred $30 \mathrm{~min}$ at $20^{\circ} \mathrm{C}$. H-Glu(OMe)-OtBu hydrochloride (2.58 g, $10.2 \mathrm{mmol}$ ) was added and the mixture was stirred for another $16 \mathrm{~h}$. The reaction mixture was filtered over celite, concentrated in vacuo to $75 \mathrm{~mL}$, and then poured slowly into a vigorously stirred solution of ice-cooled diethyl ether (2 L). The suspension was left on ice for $3 \mathrm{~h}$ and precipitate was collected by filtration and washed with cold diethyl ether. The filter cake was suspended in a mixture of EtOH: $\mathrm{H}_{2} \mathrm{O} 1: 1(150 \mathrm{~mL})$ and $\mathrm{Ba}(\mathrm{OH})_{2} \bullet \bullet \mathrm{H}_{2} \mathrm{O}(6.11 \mathrm{~g}, 13.4 \mathrm{mmol})$ was added. The suspension was stirred for $24 \mathrm{~h}$ at $20^{\circ} \mathrm{C}$ and precipitate was then removed by filtration. To the filtrate was added sat. aq. $\mathrm{Na}_{2} \mathrm{SO}_{4}(25 \mathrm{~mL})$, stored at $4{ }^{\circ} \mathrm{C}$ for $5 \mathrm{~h}$, and filtered over celite to remove precipitated $\mathrm{BaSO}_{4}$. The filtrate was acidified to $\mathrm{pH} 3$ using $0.5 \mathrm{M} \mathrm{HCl}$ and the desired product 7 was collected as an orange solid after washing $\mathrm{H}_{2} \mathrm{O}$, ether, and pentane and drying in vacuo (4.48 g, 79\%, 90\% purity). ${ }^{1} \mathrm{H}$ NMR (400 MHz, DMSO-d6) $\delta 12.17$ (br. s, 1H), 9.24 (br. s, 1H), 9.04 (br. s, 1H), 8.72 (s, 1H), 8.56 (br. s, 1H), 8.21 (d, $J=7.6$ Hz, 1H), 7.74 (d, $J=9.0 \mathrm{~Hz}, 2 \mathrm{H}$ ), 7.35 (br. s, 1H), 6.82 (d, $J=9.0 \mathrm{~Hz}, 2 \mathrm{H}$ ), 4.87 (s, 2H), 4.29 (ddd, $J=9.7$, 7.5, $5.2 \mathrm{~Hz}, 1 \mathrm{H}$ ), 3.25 (s, 3H), 2.32 (t, $J=7.5 \mathrm{~Hz}, 2 \mathrm{H}), 2.06$ - 1.96 (m, 1H), 1.90 (ddt, $J$ = 14.1, 9.3, 7.2 Hz, 1H), 1.39 (s, 9H), (Litt.[46]). ${ }^{13} \mathrm{C}$ NMR (101 MHz, DMSO-d6) $\delta$ 173.9, 171.5, 166.4, 162.8 (2C), 155.9, 151.2, 150.7, 148.8, 129.0, 122.3, 121.4, 111.2, 80.5, 54.9, 52.5, 40.2, 30.4, 27.7, 26.0, (Litt. [46]). IR (neat) cm-1: 3342, 3118, 2976, 2931, 1716, 1639, 1601, 1506, 1364, 1152, 832. 
oxothiazolidin-3-yl)pentanoate (8)

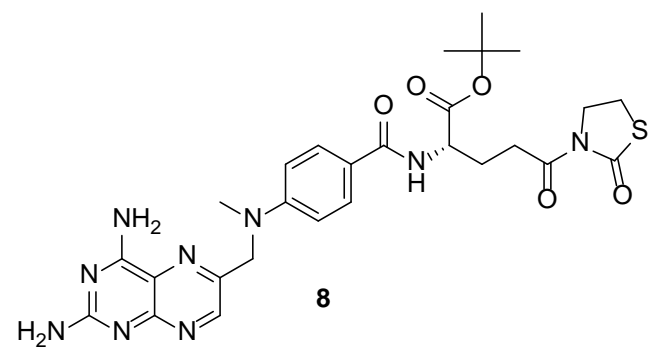

To a solution of MTX- $\alpha$-OtBu (7) (211 mg, $0.372 \mathrm{mmol}$, 90\% purity) in anhydrous DMF (5 mL) were added DCC (170 mg, $0.827 \mathrm{mmol}$ ) and DMAP (202 mg, $1.65 \mathrm{mmol}$ ) and the turbid reaction mixture was stirred for $30 \mathrm{~min}$ at $20^{\circ} \mathrm{C}$. Then, thiazolidin-2-one ( $85.3 \mathrm{mg}, 0.827 \mathrm{mmol}$ ) was added and the mixture was stirred another $16 \mathrm{~h}$. Water $(1 \mathrm{~mL})$ was added, the precipitate was removed by filtration, and the filtrate was concentrated and purified by column chromatography (water/acetonitrile $1: 19, R_{\mathrm{f}}=0.28$ ) to give the desired product 8 as a yellow solid (160 mg, 65\%, 90\% purity). mp: > $142{ }^{\circ} \mathrm{C}\left(\mathrm{dec}\right.$ ); $[\alpha]_{\mathrm{D}}^{20}=-0.7^{\circ}\left(c\right.$ 0.71, DMSO); ${ }^{1} \mathrm{H}$ NMR $(400$ MHz, DMSO-d $\left.{ }_{6}\right) \delta 8.58$ (s, 1H), 8.18 (d, $J=7.5$ Hz, 1H), 8.13 (s, 1H), 7.77 (br. s, $1 \mathrm{H}$ ), 7.71 (d, $J=9.0 \mathrm{~Hz}$, 2H), 7.56 (br. s, 1H), 6.82 (d, $J=9.0 \mathrm{~Hz}, 2 \mathrm{H}$ ), 6.71 (br. s, 2H), 4.79 (s, 2H), 4.27 (ddd, $J=9.5,7.5,5.6 \mathrm{~Hz}$, 1H), 4.04 (t, $J=7.3 \mathrm{~Hz}, 2 \mathrm{H}), 3.32$ (td, $J=7.2,1.7 \mathrm{~Hz}, 3 \mathrm{H}), 3.21$ (s, 3H), 2.88 (td, $J=7.4,2.4 \mathrm{~Hz}, 2 \mathrm{H}), 2.16$ 2.01 (m, 1H), 2.00 - 1.88 (m, 1H), 1.39 (s, 9H); ${ }^{13} \mathrm{C}$ NMR (101 MHz, DMSO-d $\left._{6}\right) \delta 173.2,172.1,171.9,166.8$, 163.5, 163.2, 154.9, 151.4, 149.6, 146.8, 129.4, 121.9, 121.5, 111.5, 80.9, 55.3, 52.9, 47.4, 40.5, 33.2, 28.1, 25.8, 25.3; IR (neat) $\mathrm{cm}^{-1}:$ 3325, 3183, 3116, 2974, 2924, 1635, 1604, 1506, 1446, 1362, 1151; HRMS (ESI) calcd. for $\left[\mathrm{C}_{27} \mathrm{H}_{34} \mathrm{~N}_{9} \mathrm{O}_{5} \mathrm{~S}\right][M+\mathrm{H}]^{+}$596.2398, found 596.2397. 


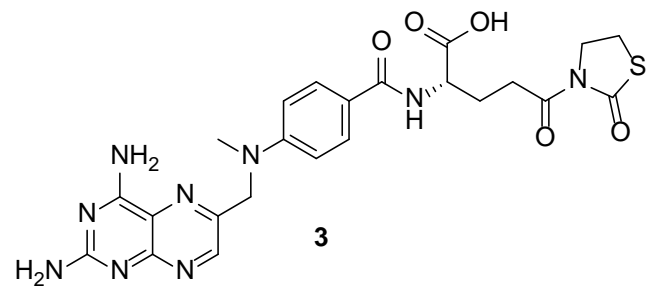

MTX- $\alpha$-OtBu- $\gamma$-TZ (8) (844 mg, 90\% purity, $1.29 \mathrm{mmol}$ ) was dissolved in pure formic acid (60 mL) and stirred for $24 \mathrm{~h}$ at $20^{\circ} \mathrm{C}$. The reaction mixture was concentrated in vacuo and the crude was dissolved in DMF (6 mL) and purified by preparative HPLC to give the desired product 3 as a light orange solid (507 mg, 74\%). mp.: > $184{ }^{\circ} \mathrm{C}$ (dec.); $[\alpha]_{\mathrm{D}}^{20}=-8.0^{\circ}\left(c\right.$ 0.48, DMSO); ${ }^{1} \mathrm{H}$ NMR (400 MHz, DMSO-d $\left.d_{6}\right) \delta 12.57$ (br. s, $\left.1 \mathrm{H}\right), 8.57$ (s, 1H), 8.18 (d, $J=7.7 \mathrm{~Hz}, 1 \mathrm{H}$ ), 7.71 (d, $J=8.9 \mathrm{~Hz}, 2 \mathrm{H}$ ), 7.65 (br. s, 1H), 7.44 (br. s, $1 \mathrm{H}$ ), 6.82 (d, $J=9.0$ Hz, 2H), 6.61 (br. s, 2H), 4.78 (s, 2H), 4.34 (ddd, $J=9.9,7.6,4.9$ Hz, 1H), $4.13-3.96$ (m, 2H), 3.32 (dt, $J=$ 7.3, $1.9 \mathrm{~Hz}, 2 \mathrm{H}), 3.20$ (s, 3H), $2.97-2.79$ (m, 2H), $2.19-2.05$ (m, 1H), 1.95 (dddd, $J$ = 13.8, 9.7, 8.0, $5.8 \mathrm{~Hz}$, 1H); ${ }^{13} \mathrm{C}$ NMR (101 MHz, DMSO-d $\left.{ }_{6}\right) \delta 174.3,173.2,172.2,166.8,163.6,163.3,155.6,151.4,149.7,146.5$, 129.4, 121.9, 121.6, 111.5, 55.3, 52.1, 47.5, 40.7, 33.4, 25.9, 25.3; IR(neat) $\mathrm{cm}^{-1}$ : 3325, 3137, 3117, 2923, 2853, 1690, 1631, 1604, 1502, 1443, 1362, 1149; HRMS (ESI) calcd. for $\left[\mathrm{C}_{23} \mathrm{H}_{26} \mathrm{~N}_{9} \mathrm{O}_{5} \mathrm{~S}\right][M+\mathrm{H}]^{+} 540.1772$, found 540.1779 .

\subsection{In vitro assays}

Phosphate buffered saline (PBS) was prepared by dissolving 1 PBS tablet in Milli-Q water (200 mL) to give a solution of $0.01 \mathrm{M}$ phosphate buffer, $0.0027 \mathrm{M} \mathrm{KCl}$, and $0.137 \mathrm{M} \mathrm{NaCl}$ with $\mathrm{pH} 7.4$ at $25{ }^{\circ} \mathrm{C}$. PBS tablets, 
human liver microsomal fractions, freeze-dried human plasma, and NADPH tetrasodium salt were purchased from Sigma-Aldrich. Assays were run in Eppendorf tubes $(1.5 \mathrm{~mL})$ and shaken using an Eppendorf Thermomixer C (1.5 mL). Analysis of the assays was performed by RP-UPLC-MS (see above, $\lambda=306 \mathrm{~nm}$ ). All experiments were performed in triplicates unless stated otherwise.

\subsubsection{Prodrug activation under different oxidative conditions and PBS stability}

To aq. PBS buffer (750 $\mu \mathrm{L}, \mathrm{pH}$ 7.4) was added a solution of prodrug (100 $\mu \mathrm{L}, 1 \mathrm{mM}$ in DMSO) followed by addition of internal standard solution (diclofenac, $100 \mu \mathrm{L}, 1 \mathrm{mM}$ in DMSO). The assay was initiated by addition of a solution of $\mathrm{H} 2 \mathrm{O} 2$ in PBS $(50 \mu \mathrm{L}, 10-5-1-0.5-0.25 \mathrm{mM})$ followed by vortex mixing. The resulting mixture was incubated at $37{ }^{\circ} \mathrm{C}$ in a Eppendorf Thermomixer C (1.5 mL, $\left.1000 \mathrm{rpm}\right)$ and samples were taken after 5, 15, 30, 60, 90 min and 2, 4, $24 \mathrm{~h}$. Analysis of the percentage of remaining compound was performed using RP-UPLC-UV ( $\lambda=306 \mathrm{~nm}$ ). A control experiment (no $\mathrm{H}_{2} \mathrm{O}_{2}$ addition but PBS, 'PBS stability’) was performed in parallel. Every prodrug activation assay was carried out in triplicates.

\subsubsection{Human plasma stability}

Freeze-dried human plasma (2 mL, Sigma-Aldrich) was reconstituted from Milli-Q water (2 mL), diluted with PBS (2 mL), and incubated for $10 \mathrm{~min}$ at $37^{\circ} \mathrm{C}$ and $300 \mathrm{rpm}$. A $1 \mathrm{mg} / \mathrm{mL}$ stock solution of 3 in DMSO was prepared. $475 \mu \mathrm{L}$ of pre-incubated human plasma solution was added to $25 \mu \mathrm{L}$ prodrug stock solution and the samples were incubated at $37^{\circ} \mathrm{C}$ at $300 \mathrm{rpm}$ along with a blank containing only human plasma (500 $\left.\mu \mathrm{L}\right)$. A zero-time reference was obtained by quenching an aliquot (50 $\mu \mathrm{L})$ in ice-cold MeCN (50 $\mu \mathrm{L})$ immediately after addition of plasma to the stock solution. The quenched sample was vortexed for $30 \mathrm{~s}$ and the resulting precipitate was removed by centrifugation (14,000 rpm, $5 \mathrm{~min}$ ). The supernatant was analyzed directly by RPUPLC-MS. Measurements were done at $30 \mathrm{~min}, 1 \mathrm{~h}, 2 \mathrm{~h}, 4 \mathrm{~h}$, and $8 \mathrm{~h}$ following the same procedure. 


\subsubsection{Microsomal stability}

In quadruplicates, $10 \mathrm{mg} / \mathrm{mL}$ human liver microsome solution $(25 \mu \mathrm{L})$ was added to PBS (425 $\mu \mathrm{L})$ and incubated at $37{ }^{\circ} \mathrm{C}$ and $1000 \mathrm{rpm}$ for $10 \mathrm{~min}$. A $10 \mathrm{mM}$ stock solution of compound 3 in DMSO and a $30 \mathrm{mM}$ stock solution of $\beta$-NADPH tetrasodium salt hydrate $(27.2 \mathrm{mg} / \mathrm{mL})$ in PBS were prepared. In quadruplicates, prodrug stock solution $(1.5 \mu \mathrm{L})$ was added to the diluted and pre-incubated microsome solution. Then, to three of the solutions NADPH stock solution $(25 \mu \mathrm{L})$ was added while PBS $(25 \mu \mathrm{L})$ was added to the remaining solution (negative control). Aliquots (50 $\mu \mathrm{L}$ ) were removed after $0 \mathrm{~min}, 5 \mathrm{~min}, 10 \mathrm{~min}, 20 \mathrm{~min}, 30 \mathrm{~min}$, and $40 \mathrm{~min}$ and added to ice-cold MeCN, vortexed for $10 \mathrm{~s}$, and stored on ice for $40 \mathrm{~min}$. Precipitated protein was removed by centrifugation (14,000 rpm, $5 \mathrm{~min}$ ) and the supernatants was analyzed by UPLC-MS. The in vitro intrinsic clearance (CL' ${ }_{\text {int }}$ in $\mathrm{mL} / \mathrm{min} / \mathrm{kg}$ protein) was calculated according to the following equation [38]:

$$
C L_{\text {int }}^{\prime}=\frac{0.693}{\text { in vitro } T_{1 / 2}} \times \frac{m \mathrm{l} \text { incubation }}{m g \text { microsomes }} \times \frac{45 \mathrm{mg} \text { microsomes }}{\mathrm{gm} \mathrm{liver}} \times \frac{20 \mathrm{gm} \text { liver }}{\mathrm{kg} \mathrm{b.w.}}
$$

\subsubsection{Thermodynamic solubility in PBS}

A $1 \mathrm{mg} / \mathrm{mL}$ stock solution of 3 in DMF was prepared. A calibration curve was constructed at 25, 50, 75, 100, and $125 \mu \mathrm{g} / \mathrm{mL}$ concentrations of this stock solution and were analyzed by RP-UPLC-MS (Figure S6, SI). Compound 3 (2 mg) was suspended in PBS (1 mL) and sonicated for $10 \mathrm{~min}$. The samples were incubated at $20^{\circ} \mathrm{C}$ and $1000 \mathrm{rpm}$ for $15 \mathrm{~h}$. The samples were centrifuged (14,000 rpm, $1 \mathrm{~min}$ ) and the supernatant was diluted in DMF (1:5) and analyzed by RP-UPLC-MS. 


\subsection{Collagen type-II-induced arthritis}

Animals: DBA/1J mice (male, $8-9$ weeks) were obtained from Janvier, France. The mice were maintained in the animal house at Redoxis, Medicon Village, Lund, Sweden, where they were acclimatized for approximately one week before initiation of the experiment. All animal experiments were approved by the local animal ethic committee Malmö/Lund, Sweden, under the license N165-15.

Induction of disease: collagen-induced arthritis (CIA) was induced by intradermal immunization with $100 \mu \mathrm{g}$ of chicken type-II collagen (CII, Chondrex) in Complete Freund's Adjuvant (CFA, Difco) on day -1 via subcutaneous injection approximately $0.5 \mathrm{~cm}$ from the root of the tail. On day 21 a boost injection was administered in the same way with $50 \mu$ g CII. One week after the second immunization injection, onset of disease started to be observed (day 26).

Anti-arthritic effect of test compounds and health evaluation: mice were randomly divided in 3 groups $(\mathrm{n}=8$ per group): group I (vehicle), group II (MTX, Sigma Aldrich, $7.0 \mathrm{mg} / \mathrm{kg}$, i.p.), group III (MTX- $\gamma$-TZ, 8.3 $\mathrm{mg} / \mathrm{kg}$, i.p.). Vehicle or test compound (2\% DMSO in PBS, Life Technologies, injection volume $370 \mu \mathrm{L}$ ) were dosed daily intraperitoneally for 14 days, starting at onset of disease (day 27). Disease was evaluated three times per week in a blinded fashion, starting at day 18 until the end of the experiment (day 40). A macroscopic scoring system of the four limbs ranging from 0 to 15 (1 point per swollen toe, 1 point per swollen foot knuckle, and 5 points for swollen ankle) was used, meaning a maximal score of 60 per mice. For ethical reasons and restrictions, mice with score exceeding 45 were removed from the experiment. The general health of mice was evaluated three times per week after disease induction. As an indicator of general health, animal body weight was used. 


\section{Acknowledgements}

We are grateful for financial support from the Independent Research Fund Denmark (grant no. 7017-00026), the Novo Nordisk Foundation (Novo Scholarship to NSA) and the Technical University of Denmark (PoC funding and a PhD scholarship for JPC). The authors declare that there is no conflict of interests in respect to the publication. 


\section{References}

[1] I.B. McInnes, G. Schett, The Pathogenesis of Rheumatoid Arthritis., N. Engl. J. Med. 365 (2011) 2205-2219.

[2] J.S. Smolen, D. Aletaha, I.B. McInnes, Rheumatoid arthritis, The Lancet. 388 (2016) 2023-2038.

[3] D.M. Lee, M.E. Weinblatt, Rheumatoid arthritis, The Lancet. 358 (2001) 903-11.

[4] M.E. Weinblatt, Methotrexate in rheumatoid arthritis: a quarter century of development., Trans. Am. Clin. Climatol. Assoc. 124 (2013) 16-25.

[5] B.N. Cronstein, Low-Dose Methotrexate: A Mainstay in the Treatment of Rheumatoid Arthritis, Rev. Pharmacol. 57 (2005) 163-172.

[6] J. Grim, J. Chládek, J. Martínková, Pharmacokinetics and Pharmacodynamics of Methotrexate in Non-Neoplastic Diseases, Clin Pharmacokinet. 42 (2003) 139-151.

[7] B. Bannwarth, F. Péhourcq, T. Schaeverbeke, J. Dehais, Clinical Pharmacokinetics of Low-Dose Pulse Methotrexate in Rheumatoid Arthritis, Clin. Pharmacokinet. 30 (1996) 194-210.

[8] J. Rautio, H. Kumpulainen, T. Heimbach, R. Oliyai, D. Oh, T. Järvinen, J. Savolainen, Prodrugs: design and clinical applications., Nat. Rev. Drug Discov. 7 (2008) 255-270.

[9] J.B. Zawilska, J. Wojcieszak, A.B. Olejniczak, Prodrugs: A challenge for the drug development, Pharmacol. Reports. 65 (2013) 1-14.

[10] J. Rautio, N.A. Meanwell, L. Di, M.J. Hageman, The expanding role of prodrugs and development, Nat. Rev. Drug Discovery. (2018). doi:10.1038/nrd.2018.46.

[11] S.S. Abolmaali, A.M. Tamaddon, R. Dinarvand, A review of therapeutic challenges and achievements of methotrexate delivery systems for treatment of cancer and rheumatoid arthritis, Cancer Chemother. Pharmacol. 71 (2013) 1115-1130.

[12] J.R. Stone, S. Yang, Hydrogen Peroxide: A Signaling Messenger, Antioxid. Redox Signaling. 8 
(2008) 243-270.

[13] C. Wittmann, P. Chockley, S.K. Singh, L. Pase, G.J. Lieschke, C. Grabher, Hydrogen peroxide in inflammation: Messenger, guide, and assassin, Adv. Hematol. 2012 (2012) 1-6.

[14] M. Gutowski, S. Kowalczyk, A study of free radical chemistry: Their role and pathophysiological significance, Acta Biochim. Pol. 60 (2013) 1-16.

[15] M. Valko, D. Leibfritz, J. Moncol, M.T. Cronin, M. Mazur, J. Telser, Free radicals and antioxidants in normal physiological functions and human disease, Int. J. Biochem. Cell Biol. 39 (2007) 44-84.

[16] M. Nagata, Inflammatory Cells and Oxygen Radicals, Curr. Drug Targets - Inflamm. Allergy. 4 (2005) 503-504.

[17] M. Mittal, M.R. Siddiqui, K. Tran, S.P. Reddy, A.B. Malik, Reactive oxygen species in inflammation and tissue injury., Antioxid. Redox Signaling. 20 (2014) 1126-67.

[18] C.A. Hitchon, H.S. El-Gabalawy, Oxidation in rheumatoid arthritis, Arthritis Res. Ther. 6 (2004) 265.

[19] C.J. Wruck, A. Fragoulis, A. Gurzynski, L.-O. Brandenburg, Y.W. Kan, K. Chan, J. Hassenpflug, S. Freitag-Wolf, D. Varoga, S. Lippross, T. Pufe, Role of oxidative stress in rheumatoid arthritis: insights from the Nrf2-knockout mice, Ann. Rheum. Dis. 70 (2011) 844-850.

[20] R. Weinstain, E.N. Savariar, C.N. Felsen, R.Y. Tsien, In Vivo Targeting of Hydrogen Peroxide by Activatable Cell-Penetrating Peptides, J. Am. Chem. Soc. 136 (2014) 1-18.

[21] R. Kumar, J. Han, H.J. Lim, W.X. Ren, J.Y. Lim, J.H. Kim, J.S. Kim, Mitochondrial induced and self-monitored intrinsic apoptosis by antitumor theranostic prodrug: In vivo imaging and precise cancer treatment, J. Am. Chem. Soc. 136 (2014) 17836-17843.

[22] A. Boveris, S. Alvarez, J. Bustamante, L. Valdez, Measurement of Superoxide Radical and Hydrogen Peroxide Production in Isolated Cells and Subcellular Organelles, Methods Enzym. 349 (2002) 280287. 
[23] S. Mueller, Sensitive and nonenzymatic measurement of hydrogen peroxide in biological systems, Free Radic. Biol. Med. 29 (2000) 410-415.

[24] X. Peng, V. Gandhi, ROS-activated anticancer prodrugs: a new strategy for tumorspecific damage, Ther Deliv. 3 (2012) 823-833.

[25] H. Hagen, P. Marzenell, E. Jentzsch, F. Wenz, M.R. Veldwijk, A. Mokhir, Aminoferrocene-based prodrugs activated by reactive oxygen species, J. Med. Chem. 55 (2012) 924-934.

[26] Y. Kuang, K. Balakrishnan, V. Gandhi, X. Peng, Hydrogen Peroxide Inducible DNA Cross-Linking Agents Targeted, J. Am. Chem. Soc. 133 (2011) 19278-19281.

[27] W. Chen, K. Balakrishnan, Y. Kuang, Y. Han, M. Fu, V. Gandhi, X. Peng, Reactive oxygen species (ROS) inducible DNA cross-linking agents and their effect on cancer cells and normal lymphocytes, J. Med. Chem. 57 (2014) 4498-4510.

[28] S. Cao, Y. Wang, X. Peng, ROS-inducible DNA cross-linking agent as a new anticancer prodrug building block, Chem. Eur. J. 18 (2012) 3850-3854.

[29] E.J. Kim, S. Bhuniya, H. Lee, H.M. Kim, C. Cheong, S. Maiti, K.S. Hong, J.S. Kim, An activatable prodrug for the treatment of metastatic tumors, J. Am. Chem. Soc. 136 (2014) 13888-13894.

[30] K.B. Daniel, J.L. Major Jourden, K.E. Negoescu, S.M. Cohen, Activation of sulfonate ester based matrix metalloproteinase proinhibitors by hydrogen peroxide, J. Biol. Inorg. Chem. 16 (2011) 313323.

[31] J.L. Major Jourden, S.M. Cohen, Hydrogen peroxide activated matrix metalloproteinase inhibitors: A prodrug approach, Angew. Chemie - Int. Ed. 49 (2010) 6795-6797.

[32] A.K. Vadukoot, S.F. Abdulsalam, M. Wunderlich, E.D. Pullen, J. Landero-Figueroa, J.C. Mulloy, E.J. Merino, Design of a hydrogen peroxide-activatable agent that specifically targets cancer cells, Bioorg. Med. Chem. 22 (2014) 6885-6892. 
[33] R.D. Hanna, Y. Naro, A. Deiters, P.E. Floreancig, Alcohol, Aldehyde, and Ketone Liberation and Intracellular Cargo Release through Peroxide-Mediated $\alpha$-Boryl Ether Fragmentation, J. Am. Chem. Soc. 138 (2016) 13353-13360.

[34] C. Perez, J.-P. Monserrat, Y. Chen, S.M. Cohen, Exploring hydrogen peroxide responsive thiazolidinone-based prodrugs, Chem. Commun. 51 (2015) 7116-7119.

[35] J. Peiró Cadahía, J. Bondebjerg, C.A. Hansen, V. Previtali, A.E. Hansen, T.L. Andresen, M.H. Clausen, Synthesis and Evaluation of Hydrogen Peroxide Sensitive Prodrugs of Methotrexate and Aminopterin for the Treatment of Rheumatoid Arthritis, J. Med. Chem. 61 (2018) 3503-3515.

[36] L. Di, E.H. Kerns, Y. Hong, H. Chen, Development and application of high throughput plasma stability assay for drug discovery, Int. J. Pharm. 297 (2005) 110-119.

[37] E.H. Kerns, L. Di, Plasma Stability, in: Drug-like Prop. Concepts, Struct. Des. Methods from ADME to Toxic. Optim., 1st ed., Elsevier Inc., London, 2008: pp. 169-177.

[38] R.S. Obach, Prediction of human clearance of twenty-nine drugs from hepatic microsomal intrinsic clearance data: An examination of in vitro half-life approach and nonspecific binding to microsomes, Drug Metab. Dispos. 27 (1999) 1350-1359.

[39] E.H. Kerns, L. Di, Solubility, in: Drug-like Prop. Concepts, Struct. Des. Methods from ADME to Toxic. Optim., 1st ed., Elsevier Inc., London, 2008: pp. 56-85.

[40] M.F. Neurath, K. Hildner, C. Becker, J.F. Schlaak, K. Barbulescu, T. Germann, E. Schmitt, P. Schirmacher, S. Haralambous, M. Pasparakis, K.H. Meyer Zum Büschenfelde, G. Kollias, E. MärkerHermann, Methotrexate specifically modulates cytokine production by T cells and macrophages in murine collagen-induced arthritis (CIA): A mechanism for methotrexate-mediated immunosuppression, Clin. Exp. Immunol. 115 (1999) 42-55.

[41] S. Sardar, Å. Andersson, Old and new therapeutics for Rheumatoid Arthritis: in vivo models and drug development, Immunopharmacol. Immunotoxicol. (2016) 2-13. 
[42] D.E. Trentham, Collagen arthritis as a relevant model for rheumatoid arthritis., Arthritis Rheum. (1982) 911-916.

[43] T. Keleva, I. Cavar, F. Culo, Biological actions of drug solvent, Period. Biol. 113 (2011) 311-320.

[44] M. Colucci, F. Maione, M.C. Bonito, A. Piscopo, A. Di Giannuario, S. Pieretti, New insights of dimethyl sulphoxide effects (DMSO) on experimental in vivo models of nociception and inflammation, Pharmacol. Res. 57 (2008) 419-425.

[45] S.M. Robillard, H. Cruell, Patent: US 2010/0227798 A1, 2010.

[46] A. Warnecke, I. Fichtner, G. Saß, F. Kratz, Synthesis, cleavage profile, and antitumor efficacy of an albumin-binding prodrug of methotrexate that is cleaved by plasmin and cathepsin B, Arch. Der Pharm. 340 (2007) 389-395. 